\title{
Spontaneous carotid dissection
}

\author{
Carolina Dutra Queiroz Flumignan ${ }^{1}$, Ronald luiz Gomes Flumignan ${ }^{2 *}$, Luis Carlos Uta Nakano ${ }^{2}$, Jorge Eduardo de Amorim ${ }^{2}$ \\ ${ }^{1}$ MD, Research Physician, Escola Paulista de Medicina da Universidade Federal de São Paulo (EPM-Unifesp), São Paulo, SP, Brazil \\ ${ }^{2} \mathrm{MD}$, PhD, Adjunct Professor, EPM-Unifesp, São Paulo, SP, Brazil
}

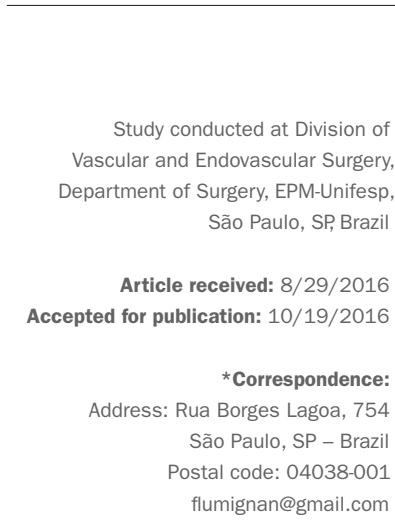

\section{SUMmarY}

Carotid dissection is a rare occurrence but it is the main cause of stroke in individuals aged less than 45 years, and can be the etiology in up to $25 \%$ of strokes in young adults. We report a case with classic image of ying yang on vascular ultrasound, which was treated according to the best available medical evidence, yielding a favorable outcome.

Keywords: carotid artery internal dissection, evidence-based medicine, platelet aggregation inhibitors, stroke, Doppler ultrasonography.

\section{INTRODUCTION}

Carotid dissection (CD) accounts for only 1-2\% of all ischemic strokes. In young individuals and middle-aged adults, however, this etiology accounts for $10-25 \%$ of these events. ${ }^{1}$ Population incidence is around 1.7 to $3 / 100,000$ per year, but it is the main cause of stroke in people aged less than 45 years. ${ }^{2}$ Etiopathogenesis is still controversial but it is believed that an association of genetic predisposition (Ehler-Danlos syndrome, Marfan, fibromuscular dysplasia, osteogenesis imperfecta, etc.), environmental factors (recent infection, trauma or cervical manipulation) and risk factors (hypertension, migraine, low cholesterol levels, and body mass index) may lead to the development of CD. ${ }^{1-9}$ Clinical presentation varies according to the artery involved. Ipsilateral headache and focal symptoms are often associated with the area of cerebral or retinal ischemia. After clinical suspicion, additional diagnostic tests are essential for diagnostic confirmation. Despite the good accuracy of Doppler ultrasonography, confirmation with magnetic resonance imaging (MRI) or computed tomography (CT scan) is still routine. Endovascular angiography, as a resource in the diagnostic stage, is used with caution due to the possibility of iatrogenic worsening. ${ }^{1}$

\section{Case report}

A 52-year-old female patient, caucasian, homemaker, complaining of left hemicranial headache and speech difficulty upon awakening three hours earlier. She denied previous episodes and other complaints such as paresis or paresthesia. She denied smoking, hypertension, diabetes, trauma, migraine, recent infection, dyslipidemia, use of oral contraceptives or any other significant personal or family history. On admission, she presented dysphasia with no motor or sensory deficits on neurological examination. No signs of intracranial hemorrhage were found on non-contrasted cranial CT scan, and the intravenous contrast phase showed no evident ischemic area. Cerebral angiography of supra-aortic trunks revealed a suggestive pattern of bilateral fibromuscular dysplasia in the distal third of the internal carotid arteries ("stacked coins" appearance) and dissection of the left internal carotid artery with stenosis of $70-80 \%$ of the lumen due to subintimal hematoma in left internal carotid artery (Figure 1). The patient was conservatively treated with acetylsalicylic acid (ASA) $100 \mathrm{mg} /$ day and clopidogrel $75 \mathrm{mg} /$ day. She showed favorable progression, without recurrence of stroke, and with progressive speech recovery six months after the event. Currently, the lesion area corresponding to language in the left cerebral hemisphere can be identified on gadolinium-enhanced magnetic resonance imaging (Figure 2). Color Doppler vascular ultrasound (CDUS) at six months after the event revealed that left internal carotid dissection with false lumen ending in a cul-de-sac remains. A bidirectional flow is observed: normal in the cranial direction and reverse in the central direction, with a classic image of ying yang on CDUS, which extended for about $4 \mathrm{~cm}$ from the carotid bulb and did not cause significant lumen stenosis (Figure 3). Systolic peak velocities were very 

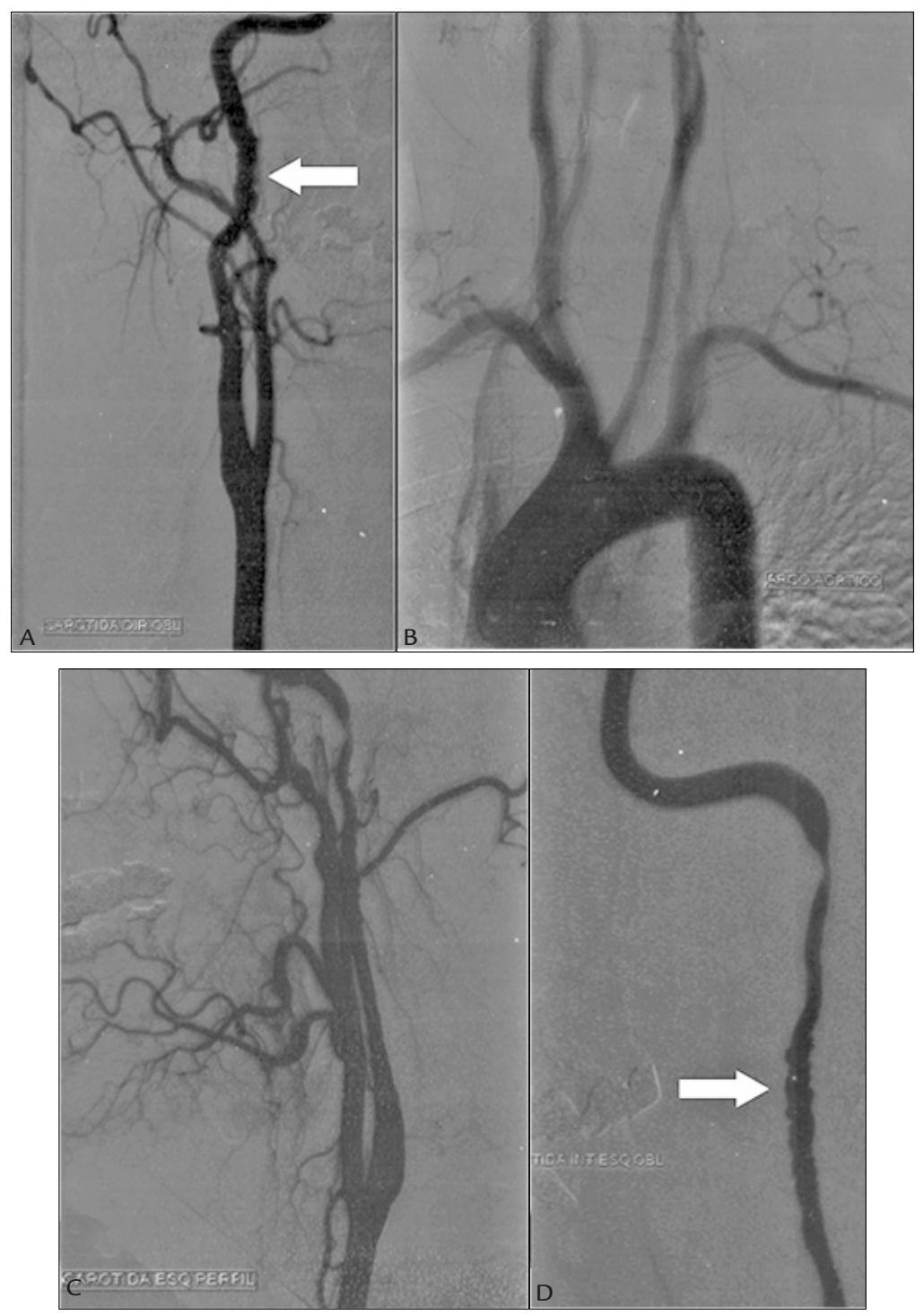

FIGURE 1 Digital fluoroscopy angiography. A. Right carotid, oblique view. B. Aortic arch, oblique view. C. Left carotid, lateral view (profile). D. Left internal carotid artery, oblique view. Arrows: "stacked coins" appearance.

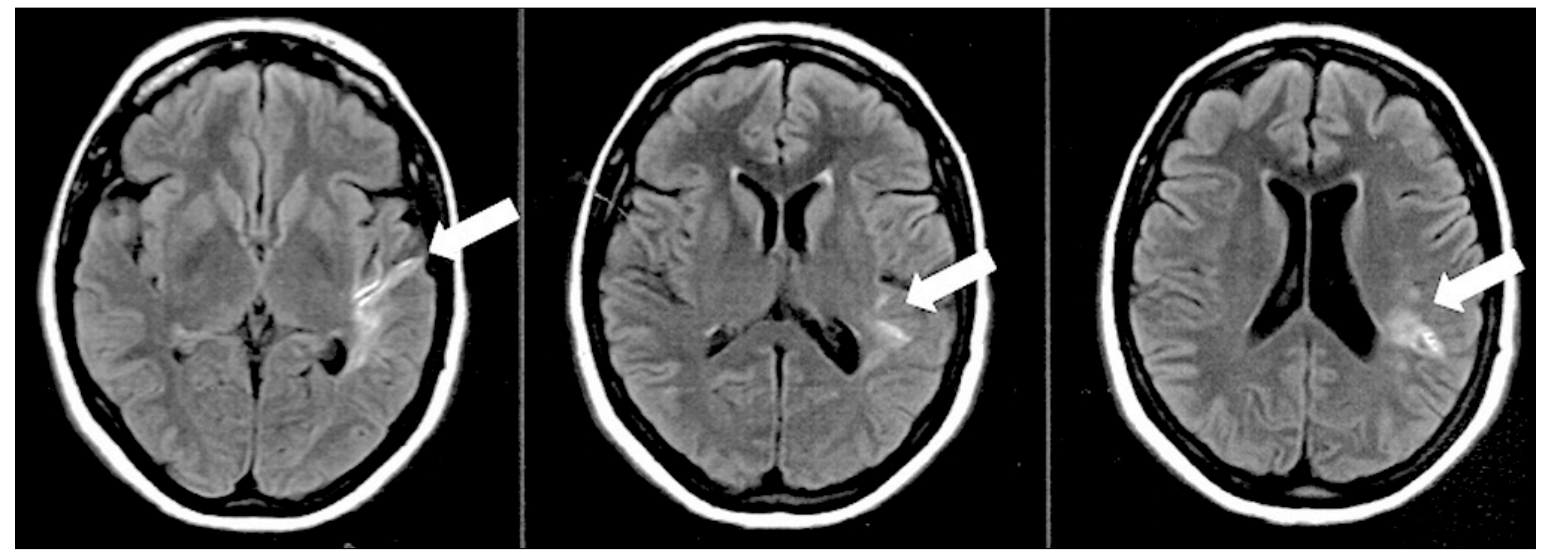

FIGURE 2 Gadolinium-enhanced T1-weighted cranial magnetic resonance imaging, six months after initial event. Arrows: area of ischemia. 


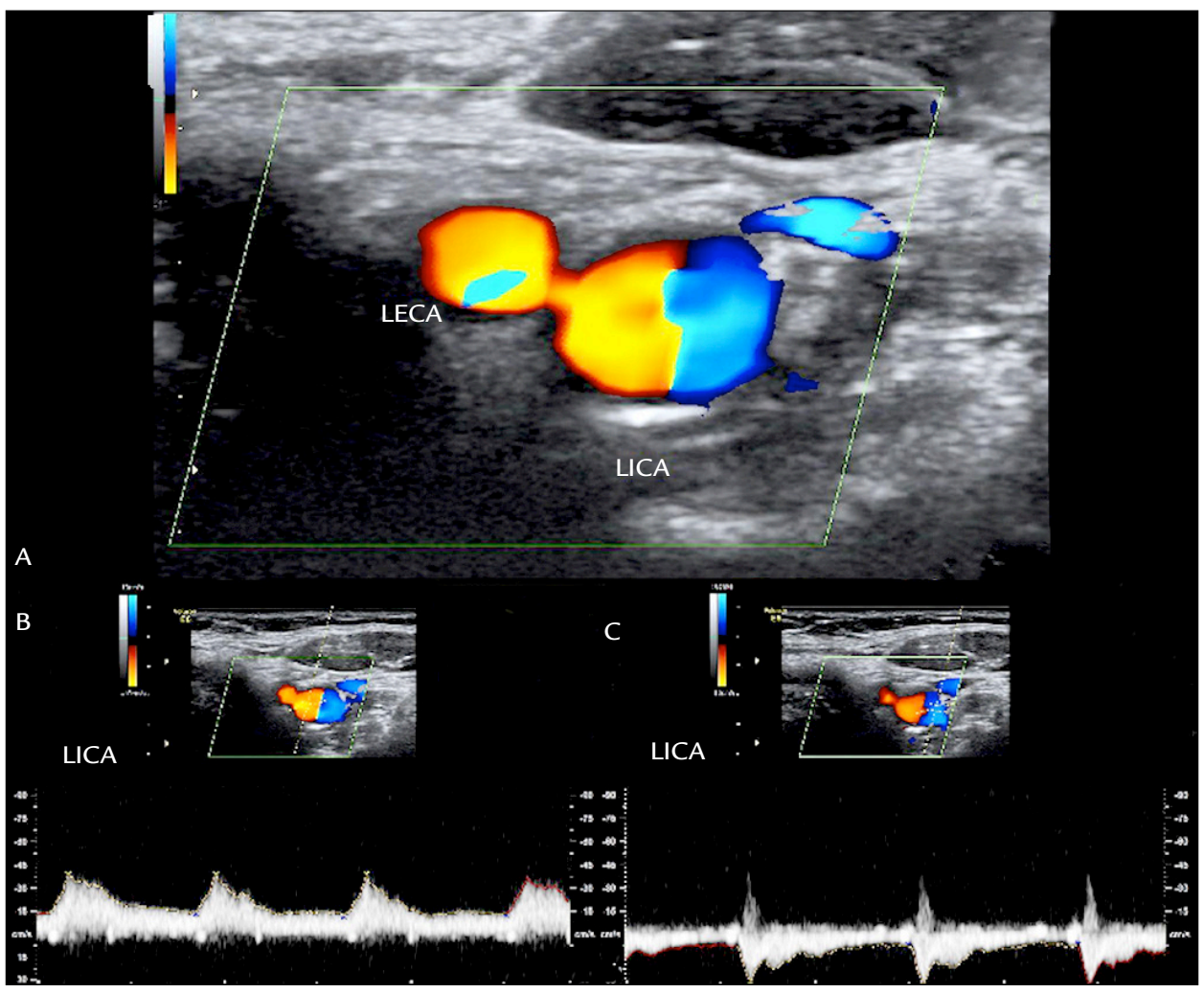

FIGURE 3 Doppler vascular ultrasound, six months after initial event. A. Color mode with yingyang image. B. Spectral mode, true lumen. C. Spectral mode, false lumen. LICA: left internal carotid artery; LECA: left external carotid artery.

similar (true lumen: $37 \mathrm{~cm} / \mathrm{s}$, and false lumen: $31 \mathrm{~cm} / \mathrm{s}$ ). This evidenced the high flow character in the false light, but without causing significant stenosis in the true light. No subintimal carotid hematoma was identified. The evaluation of renal arteries on CDUS did not confirm a typical pattern of fibromuscular dysplasia with a succession of dilatations and stenoses ("string of beads"). Then, clopidogrel was suspended, while ASA was maintained at a dose of $100 \mathrm{mg} /$ day. The patient remained with no recurrence of stroke after one year of conservative treatment. She had complete remission of dysphasia and showed, on CDUS, a reduction in the extent of dissection to $1 \mathrm{~cm}$, without hematoma or significant stenosis.

\section{Discussion}

The case corroborates the epidemiology of $\mathrm{CD}$, having occurred in a young adult and affected the internal carotid artery hereafter the bifurcation as seen in up to $2.5 \%$ of all cases of stroke. ${ }^{1}$ The only probable risk factor was the suggestive pattern of fibromuscular dysplasia on carotid endovascular angiography. The situation illustrates multifactorial etiopathogenesis and the difficulty in establishing a specific etiology. Currently, the main scientific evidence for clinical decision making is a systematic review of randomized clinical trials. ${ }^{10,11}$ A Cochrane systematic review of randomized clinical trials on antithrombotic drugs for carotid artery dissection conducted in 2010 yielded no evidence in this regard. ${ }^{2}$ In 2015, however, new evidence was produced. A randomized clinical trial found no significant difference between treatment with anticoagulants or antiplatelet agents to prevent death and stroke in symptomatic dissection of carotid or vertebral arteries. ${ }^{12}$ In this clinical trial, recurrent events were much rarer than in previous observational studies, and the initial diagnosis of dissection was quite misleading after a thorough review of the images. This shows that radiographic criteria are not always correctly applied in clinical practice. Lower levels of evidence report that endovascular treatments, such as angioplasty with stenting or thrombolysis, may be superior to conservative treatment in selected populations. ${ }^{13-16}$ The case presented is in line with the best scientific evidence available at the time. The patient underwent conservative treatment with antiplatelet agents and did not present recurrence of stroke or death within one year of follow-up.

Although rare, CD should always permeate the diagnostic suspicion in cases of stroke, especially in young patients and/or those with risk factors for developing the 
disease. Diagnostic confirmation and follow-up should include non-invasive ancillary methods, with thorough collection and evaluation of these images. The best level of available evidence still recommends conservative treatment as a general measure, either with anticoagulation or anti-platelet aggregation.

\section{AcKnowledgments}

We thank the patient for authorizing her case report.

\section{Resumo}

\section{Dissecção espontânea de carótida}

A dissecção de carótida é entidade rara, mas é a principal causa de acidentes vasculares cerebrais isquêmicos em menores de 45 anos e pode ser a etiologia de até $25 \%$ dos acidentes vasculares cerebrais em adultos jovens. Apresenta-se um caso com imagem clássica de ying yang à ultrassonografia vascular, que foi tratado de acordo com as melhores evidências médicas disponíveis e apresentou boa evolução.

Palavras-chave: dissecção da artéria carótida interna, medicina baseada em evidências, inibidores da agregação de plaquetas, acidente vascular cerebral, ultrassonografia Doppler.

\section{References}

1. Blum CA, Yaghi S. Cervical artery dissection: a review of the epidemiology, pathophysiology, treatment, and outcome. Arch Neurosci. 2015; 2(4):e26670.

2. Lyrer P, Engelter S. Antithrombotic drugs for carotid artery dissection. Cochrane Database Syst Rev. 2010; (10):CD000255.

3. Rusu O, Vasile M, Bajenaru O, Antochi F. Evolution of internal carotid artery occlusion in non-traumatic carotid dissection. Mædica (Buchar). 2014; 9(2):194-7.
4. Nasser M, Vega MB, Pivetta LGA, Nasser AI, Melo DG. Internal carotid artery dissection in a patient with Ehlers-Danlos syndrome type IV: diagnosis and management. J Vasc Bras. 2013; 12(2):174-9.

5. Campos CR, Bassi TG, Pinto F, Abrahão DKP. [Internal carotid artery dissection in a patient with recent respiratory infection: case report of a possible link]. Arq Neuropsiquiatr. 2005; 63(2B):523-6.

6. Campos-Herrera CR, Scaff M, Yamamoto FI, Conforto AB. Spontaneous cervical artery dissection: an update on clinical and diagnostic aspects. Arq Neuropsiquiatr. 2008; 66(4):922-7.

7. Pieri A, Spitz M, Valiente RA, Avelar WM, Silva GS, Massaro AR. Dissecção espontânea das artérias carótidas e vertebrais em uma população multiétnica. Arq Neuropsiquiatr. 2007; 65(4A):1050-5.

8. Marin LF, Bichuetti DB, Felício AC, Santos WAC, Oliveira FF, Morita $\mathrm{ME}$, et al. Hypoglossal nerve palsy as the sole manifestation of spontaneous internal carotid artery dissection. Arq Neuropsiquiatr. 2009; 67(1):107-8

9. Silvariño R, Mérola V, Firpo M, Pino A, Fraga L, Tafuri J, et al. Disección espontánea de carótida interna como causa de accidente cerebrovascular isquémico en el joven. Arch Med Int. 2009; 31(1):37-9.

10. Howick J, Chalmers I, Glasziou P, Greenhalgh T, Heneghan C, Liberati A, et al. Explanation of the 2011 Oxford Centre for Evidence-Based Medicine (OCEBM) Levels of Evidence (Background Document); 2011 [cited 2016 Mar 3]. Available from: http://www.cebm.net/index.aspx?o $=5653$.

11. OCEBM Levels of Evidence Working Group. The Oxford 2011 Levels of Evidence; 2011 [cited 2016 Mar 3]. Available from: http://www.cebm.net/ index.aspx?o $=5653$

12. CADISS trial investigators, Markus HS, Hayter E, Levi C, Feldman A, Venables $\mathrm{G}$, et al. Antiplatelet treatment compared with anticoagulation treatment for cervical artery dissection (CADISS): a randomised trial. Lancet Neurol. 2015; 14(4):361-7.

13. Huang R, Niu L, Wang Y, Jia G, Jia L, Wang Y, et al. Endovascular versus non-interventional therapy for cervicocranial artery dissection in east Asian and non-east Asian patients: a systematic review and meta-analysis. Sci Rep. $2015 ; 5: 10474$.

14. Tsivgoulis G, Zand R, Katsanos AH, Sharma VK, Goyal N, Krogias C, et al. Safety and outcomes of intravenous thrombolysis in dissection-related ischemic stroke: an international multicenter study and comprehensive meta-analysis of reported case series. J Neurol. 2015; 262(9):2135-43

15. Haussen DC, Jadhav A, Jovin T, Grossberg JA, Grigoryan M, Nahab F, et al. Endovascular management vs intravenous thrombolysis for acute stroke secondary to carotid artery dissection: local experience and systematic review. Neurosurgery. 2016; 78(5):709-16.

16. Engelter ST, Dallongeville J, Kloss M, Metso TM, Leys D, Brandt T, et al.; Cervical Artery Dissection and Ischaemic Stroke Patients-Study Group. Thrombolysis in cervical artery dissection--data from the Cervical Artery Dissection and Ischaemic Stroke Patients (CADISP) database. Eur J Neurol. 2012; 19(9):1199-206. 